\title{
LIVROS DIDÁTICOS: AUTORIA EM QUESTÃO
}

\author{
Adriana Soares Ralejo ${ }^{1}$ \\ Ana Maria Monteiro ${ }^{2}$
}

\begin{abstract}
Resumo: A autoria de livros didáticos tem ocupado, em nossa sociedade, um lugar secundarizado em parte decorrente da desvalorização dos conhecimentos e materiais produzidos na/para a instituição escolar. Reconhecendo a relevância de pesquisas que buscam compreender a especificidade e complexidade dessa produção, discutimos, em diálogo com as teorizações foucaultianas sobre "o que é um autor", a autoria de livros didáticos em perspectiva de investigação que a considera uma função discursiva, constituinte de sujeitos em contextos nos quais saberes e poderes são disputados, negociados, validados. Essa questão é discutida no âmbito das políticas públicas e do mercado editorial brasileiro, no qual profundas transformações têm afetado as condições e possibilidades do exercício desta função, reposicionando sujeitos e suas produções.
\end{abstract}

Palavras-chave: Livro didático. Autoria. Ensino de história. Currículo. Sujeito.

\section{TEXTBOOKS: AUTHORSHIP IN QUESTION}

\begin{abstract}
The authorship of textbooks has occupied a secondary place in our society, partly due to the devaluation of knowledge and materials produced in/for the school institution. Recognizing the relevance of research that seeks to understand the specificity and complexity of this production, we discussed, in dialogue with Foucault's theorizations about "what an author is", the authorship of didactic books in an investigation perspective that considers it a discursive function, a constituent of subjects in contexts in which knowledge and powers are disputed, negotiated, validated. This issue is discussed in the scope of public policies and the Brazilian publishing market, in which profound changes have affected the conditions and possibilities of exercising this function, repositioning subjects, and their productions.
\end{abstract}

Keywords: Textbook. Authorship. History teaching. Curriculum. Subject.

\section{MANUELS SCOLAIRES: LA PROPRIÉTÉ INTELLECTUELLE EN QUESTION}

Résumé: L'auteurs des manuels scolaire ont occupé une place secondaire dans notre société, en partie à cause de la dévaluation des connaissances et des matériaux produits dans / pour l'établissement scolaire. Reconnaissant la pertinence d'une recherche qui cherche à comprendre la spécificité et la complexité de cette production, nous avons discuté, en dialogue avec les théorisations de Foucault sur "Qu'est - ce qu'un auteur», l'auteurs des manuels dans une perspective d'investigation qui la considère comme une fonction discursive, constituant des sujets dans des contextes où les connaissances et les pouvoirs sont contestés, négociés, validés. Cette question est abordée au regard des politiques publiques et du marché brésilien de l'édition, où de profonds changements ont affecté les conditions d'exercer cette fonction, ayant repositionné les sujets et leurs productions.

Mots-clés: Manuel scolaire. Propriété intelectuelle. Enseignement de l'histoire. Curriculum. Sujet.

\footnotetext{
${ }^{1}$ Doutora em Educação (UFRJ). Pesquisadora em ensino de História do GEHPROF/UFRJ.

2 Doutora em Educação (PUC-RIO). Professora titular da Faculdade de Educação da Universidade Federal do Rio de Janeiro. Pesquisadora CNPq.
} 


\section{LIBROS DE TEXTO: AUTORÍA EN CUESTIÓN}

Resumen. La autoría de los libros de texto ha ocupado un lugar secundario en nuestra sociedad, en parte debido a la devaluación del conocimiento y de los materiales producidos en/para la institución escolar. Reconociendo la relevancia de la investigación que busca comprender la especificidad y complejidad de esta producción, discutimos, en diálogo con las teorizaciones de Foucault sobre "qué es un autor", la autoría de los libros de texto en una perspectiva de investigación que la considera una función discursiva, que constituye sujetos en contextos en que los conocimientos y poderes son disputados, negociados, validados. Este tema se discute en el ámbito de las políticas públicas y del mercado editorial brasileño, en que los cambios profundos han afectado las condiciones y posibilidades de ejercer esta función, reposicionando temas y sus producciones.

Palabras-clave: Libro de texto. Autor. Enseñanza de historia. Currículo. Sujeto.

\section{Introdução}

Tenho o privilégio de não saber quase tudo (Manoel de Barros)

O que caracteriza um autor de livro didático? Para responder a essa pergunta, precisamos esmiuçá-la e desenvolvê-la: o que é um autor? Existe um sujeito que o delimita? O que é e quais são as funções de um livro didático em tempos atuais? Objetos de estudo valorizados ou prestes a ser descartados como anacrônicos? Qual o seu impacto para o ensino de História em um cenário de disputas e diálogos com outras formas de saber? Qual a importância de um autor de livros didáticos? Essa autoria é reconhecida e valorizada academicamente? O que a torna "menor" frente a de um livro acadêmico?

Esses questionamentos estão relacionados à pesquisa desenvolvida no âmbito do Grupo de Estudos e Pesquisas em Ensino de História e Formação de Professores/GEHPROF/UFRJ. Nossas discussões e pesquisas articulam referências sobre currículo entendido como uma produção híbrida cultural $^{3}$ na qual práticas docentes expressam opções e processos de mediação realizados na/para atribuição de sentidos aos saberes ensinados/aprendidos em contexto marcado pela intencionalidade educativa.

\footnotetext{
3 Produção híbrida cultural expressa concepção sobre currículo entendido como "produção dos docentes/agentes culturais em diálogo com seus alunos, em contextos curriculares específicos. Estes podem estar constituídos em uma sala de aula, uma atividade museal, um texto de livro didático, uma dinâmica na modalidade EAD, considerados em seus aspectos contingenciais, nos quais circulam diferentes sentidos e demandas de conhecimento: fluxos oriundos dos conhecimentos científicos que se articulam com referências culturais dos diferentes sujeitos em diálogo e das instituições onde se efetivam as mediações/produções/práticas articulatórias/negociações, no movimento constitutivo do "ensino de" no fazer curricular (MONTEIRO, 2015, p. 166).
} 
DOI: $10.47694 /$ issn.2674-7758.v2.i5.2020.117134

Assim, uma questão que nos é cara é a valorização da prática docente e a busca da compreensão dos saberes e práticas mobilizados no exercício da atuação profissional. Entendemos a docência como um ato de ensinar/aprender, mas também de produzir conhecimentos na especificidade do contexto escolar. A prática docente se constitui em um espaço-tempo de fronteira cultural (MACEDO, 2006), no qual saberes são produzidos e mobilizados em contextos sócio-político-culturais, em que opções e processos de mediação são realizados na busca de atribuição de sentidos ao conhecimento escolar a ser ensinado.

Nesse sentido, a prática docente/fazer curricular torna-se um dos focos de nossa investigação na busca da compreensão dos processos de sua constituição e de sua epistemologia, tendo como pressuposto que o conhecimento histórico escolar é uma produção curricular, um híbrido cultural no qual se articulam fluxos do conhecimento científico (GABRIEL e MORAES, 2014), saberes dos alunos e dos professores e referências culturais mais amplas. Nesta perspectiva de abordagem temos investigado a relação dos professores com os saberes que ensinam nos diversos contextos possíveis de sua atuação profissional nos quais possibilidades de exercício da prática docente pode se manifestar.

As fontes e as análises realizadas, a metodologia empregada e as discussões proporcionadas têm possibilitado a emergência de pesquisas por estudantes dos cursos de pós-graduação integrantes do grupo de pesquisa. $O$ conjunto dessas teses e dissertações nos permite compreender que o foco na relação com o saber na prática docente e na produção do conhecimento escolar em diferentes contextos curriculares tem possibilitado a formulação de questões que expressam articulações possíveis no âmbito desse grupo, no qual a pesquisa central representa um eixo troncal que ganha ramificações por meio das pesquisas a ela vinculadas.

Uma dessas ramificações é representada pela pesquisa sobre o universo de produção de livros didáticos de História, desenvolvida na forma de tese de doutorado. Esta investigação teve por objetivo compreender o papel de sujeitos reconhecidos como autores no jogo entre saberes e poderes, em práticas discursivas orientadas por regras enunciativas em narrativas didáticas materializadas no formato de livros didáticos. É com base nesta produção que estabelecemos, neste artigo, uma discussão que focaliza uma relação entre sujeitos, saberes e currículo.

Em nossas pesquisas em ensino de História, mais especificamente, ao nos situarmos em um lugar de diálogo com as questões curriculares, estamos na busca da 
DOI: $10.47694 /$ issn.2674-7758.v2.i5.2020.117134

compreensão das lutas por significação no âmbito dessa disciplina. Afinal, quem decide o que ensinar? Documentos oficiais exercem influência sobre as práticas docentes, mas não de forma hierárquica e, sim, em um ciclo de relações que envolve diferentes sujeitos (BALL, 2001). Entendendo o currículo como um híbrido cultural, é preciso compreender os diferentes fluxos de saber e poder mobilizados na produção do conhecimento histórico escolar. E um dos objetos que exerce grande influência nesse processo de ensino é o livro didático. Ora desvalorizado, ora julgado como manipulador de ideologias, mesmo com todas as críticas que esse instrumento de ensino tem recebido, sua presença ainda é muito forte nos diversos usos que possa ter dentro do contexto escolar.

E mesmo em um ambiente em que o mundo digital se faz cada vez mais presente em sala de aula, esse objeto permanece, reconhecido como necessário para professores e alunos. Em muitos casos, o livro didático é o único material de referência a que uma criança terá acesso em sua casa. Sua formatação de conteúdos organizados de forma própria para o ensino, com uma linguagem já didatizada, facilita seu processo de aprendizagem. Para docentes, se torna material de apoio, guia para os conteúdos a serem ensinados, objeto de consulta, pesquisa e atualização (MONTEIRO, 2009, p. 177-199). Podemos nos questionar: por que dessa permanência? O que faz do livro didático um instrumento tão demandado na escola? Um objeto que emerge no cenário escolar no século XIX ainda não entrou em desuso (passando pelas modificações e adaptações de acordo com o seu tempo histórico).

Por possuir um papel de portador do conhecimento escolar e de divulgador de um ideário educacional para a formação do aluno e do professor, este instrumento viabiliza, de forma mais prática e eficiente, a incorporação de reformas curriculares se comparado aos próprios programas prescritos. Além disso, tem se mostrado um objeto de grande eficácia na educação para induzir melhorias considerando o baixo custo de produção que o material exige (BITTENCOURT, 2008; CASSIANO, 2013; GATTI JR, 2004). Assim, livros didáticos e os programas educacionais têm sido produzidos concomitantemente, um auxiliando o outro na elaboração de conteúdos (BITTENCOURT, 2008) e, no caso em pauta, consolidando o conhecimento histórico escolar (MONTEIRO, 2019).

Ao compreender que os conteúdos prescritos nos livros didáticos são selecionados, organizados e significados, entendemos que esses materiais não são objetos que surgem do acaso, mas produtos de seu tempo, que passam por modificações 
DOI: $10.47694 /$ issn.2674-7758.v2.i5.2020.117134

de acordo com o contexto no qual estão inseridos (RALEJO, 2018). Seguindo essa linha de pensamento, citamos os trabalhos de Circe Bittencourt (2004, 2008) e Arlette Gasparello (2013) que se dedicaram a investigar a trajetória de produção e uso dos livros didáticos desde o século XIX, analisando implicações político-culturais no processo de construção de identidades e da ideia de nação. Em estudos sobre esses objetos de ensino na contemporaneidade, destacamos os trabalhos de Kazumi Munakata (1997, 2009, 2012, 2016) e Décio Gatti Júnior (2004, 2007) que aprofundam a análise na busca da compreensão das relações entre autores e editores rompendo com visões dicotômicas.

Esses trabalhos foram produzidos no contexto do processo de redemocratização no país, quando o ensino de História se constituía como um problema e se intensificavam as políticas de controle e qualidade sobre o conhecimento histórico escolar (RALEJO, 2018). É interessante observar que, dentro de um cenário em que emergiam as críticas ao livro didático como objetos de caráter ideológico, denunciados por serem permeados de erros e preconceitos, esses autores se destacam por buscar compreender seu processo de constituição, contextualizando-os em seu tempo e lugar. Objetos culturais complexos, além das questões econômicas, reconhecemos hoje que estão envolvidos em relações de poder relacionadas aos processos de produção, distribuição e consumo desse material (BITTENCOURT, 2008).

Essas pesquisas nos alertam sobre a importância de se compreender o que é um autor de livro didático e qual o papel que desempenha, objeto ainda pouco investigado. Afinal, a esse sujeito é atribuída a autoridade de quem realiza escolhas, dialoga com as demandas externas como as políticas públicas, editores, acadêmicos, professores, pais e alunos e precisa, dentro desse contexto, escrever algo. Mas escrever não é um ato simples e a autoria ganha uma complexidade ao observarmos mais de perto a função que ele desempenha no contexto educacional.

Escolher o que deve ou não ser ensinado é um ato político (GABRIEL, MORAES, 2014, p. 28). E, pensando nisso, entendemos que a autoria de livros didáticos carrega consigo a subjetividade de produção e articulações estabelecidas com demandas que estão fora desse lugar e que acabam constituindo ideias de verdade, validadas como conhecimento. E como todo discurso, materializado no livro didático, esta articulação é contingente e variável, se criando de forma específica.

Para então compreender um pouco mais a complexidade envolvida no que é se constituir um autor de livro didático, apresentamos, neste artigo discussões que temos 
desenvolvido no âmbito do grupo de pesquisa para pensar a autoria como uma função discursiva, um lugar de produção de significados. A partir das contribuições teóricas de Michel Foucault $(2001,2012)$, traçamos novos olhares sobre a autoria em tempos atuais, estabelecendo relações com os livros didáticos, com o currículo, e com os saberes mobilizados.

\section{A autoria e sua relação com o sujeito}

Quando pensamos no universo de produção de livros didáticos e o papel da autoria nesse processo, nos questionamos se existe espaço de autonomia em suas práticas tão fortemente reguladas por instrumentos políticos, econômicos e sociais, oficiais e não-oficiais. O que vem a ser uma prática autônoma e até onde ela é possível? Como se constituem os processos de subjetivação no qual autores estão inseridos? Podemos considerar os escritores como produtores de um tipo de conhecimento escolar? Existe autoria em suas práticas como formas de resistência?

Com esses questionamentos, nos lançamos primeiramente para a nossa questão central: o que é ser autor de livro didático e qual é o seu papel na produção curricular? $\mathrm{Na}$ busca pelo significado de "autor", encontramos nas pesquisas de Foucault (2001) caminhos para o desenvolvimento desta questão.

De onde surge a "vontade de saber" de Foucault em falar sobre o autor? Em conferência proferida originalmente em 1969 na Societé Française de Philosophie, intitulada “Qu'est-ce qu'un auteur?”, Foucault usa dessa oportunidade para responder às críticas recebidas em sua obra "As palavras e as coisas" (1966) quanto ao uso de autores como referenciais teóricos de forma ambígua. Ao fazer uma reflexão sobre sua prática de escrita, Foucault busca compreender sobre o funcionamento do discurso e o papel que representam autor e obra ao individualizar algo maior, os diversos discursos nos quais estão inseridos. Em um diálogo com Roland Barthes, Foucault reflete sobre a indiferença por quem fala, o que constituiria no que Barthes (2004) chama de "morte do autor".

O que seria essa “morte do autor”? Ao usar essa expressão, Barthes faz alusão ao empoderamento da escrita que apaga o sujeito-autor ao dar um lugar de poder ao texto como discurso. Nessa linha teórica, a escrita passa a falar por si, e seus sentidos são construídos pelo leitor, dispensando a presença de seu "proprietário". Os desdobramentos 
da escrita, ou seja, os significados que lhe são atribuídos ganha maior destaque no lugar daquele que escreve ${ }^{4}$.

Há um segundo sentido sobre essa morte do autor destacada por Foucault. Neste caso, a morte do autor está ligada ao seu desaparecimento de forma proposital quando este despista signos de sua individualidade particular para atribuir à sua obra a consagração da imortalidade. Imortalidade no sentido de caráter de verdade, ou seja, legitimando seu trabalho como representação do "verdadeiro" conhecimento sem abrir brechas para que surjam argumentos que possam criticar a procedência das informações ali presentes. Quando a escrita ganha um empoderamento, ela fala por si. Se ela é relacionada como um produto, fruto de ideias individuais, esta pode ser criticada pelos valores de seu tempo e da mão que a escreveu. Assim, o autor faz "papel de morto" no jogo da escrita e se torna um herói, assim como os heróis gregos que viam a morte como a consagração para a imortalidade (FOUCAULT, 2001).

Foucault não nega a existência de alguém que escreve, mas considera que a autoria não está ligada a uma pessoa, mas a uma função da ordem do discurso.

Seria absurdo negar, é claro, a existência do indivíduo que escreve e inventa. Mas penso que - ao mesmo desde certa época - o indivíduo que se põe a escrever um texto no horizonte no qual paira uma obra possível retoma por sua conta a função do autor: aquilo que ele escreve e o que não escreve, aquilo que desenha, mesmo a título de rascunho provisório, como esboço da obra, e o que deixa, vai cair como conversas cotidianas. Todo este jogo de diferenças é prescrito pela função do autor, tal como a recebe de sua época ou tal como ele, por sua vez, a modifica. Pois embora possa modificar a imagem tradicional que se faz de um autor, será a partir de uma nova posição do autor que recortará, em tudo que poderia ter dito, em tudo o que diz todos os dias, a todo o momento, o perfil ainda trêmulo de sua obra. (FOUCAULT, 2012, p. 27-28).

É dessa forma que Foucault passa a considerar a existência de autoria: como uma função. Um ano depois da conferência realizada em 1969, o filósofo retoma o assunto da autoria em "A ordem do discurso". Nesta ocasião, a questão da autoria é tratada como um procedimento que faz parte do discurso, o que não nega a existência do

\footnotetext{
${ }^{4}$ Foucault (2001) manifesta sua preocupação com a presença/ausência do autor quanto à designação de suas obras. Porém, ao contrário de Barthes, não acredita que haja realmente uma morte, e sim uma ausência das marcas autorais ocasionada pelos caminhos da escrita contemporânea. Assim, a noção de autor foi ressignificada por meio de regras históricas e culturais de seu funcionamento em nossa sociedade. O historiador Roger Chartier $(1994 ; 2014)$ tem desenvolvido pesquisas em diálogo com Foucault também ao problematizar a autoria no contexto de produção de livros e na interferência do editor. Mas neste trabalho buscamos destacar uma abordagem discursiva, enquanto Chartier destaca uma perspectiva histórica de livros, autores e editores, bem como a tensão entre a imposição do texto e a liberdade do leitor. A questão do leitor não é objeto de discussão neste artigo.
} 
sujeito. Sabemos que existe uma inquietação provocada na linguagem, alguém que em meio às palavras, rompe, traz seu gênio e sua desordem (FOUCAULT, 2012, p. 27).

Mas não é o indivíduo e suas experiências pessoais que está em jogo, porque isso muda de acordo com as especificidades temporais e discursivas nas quais está inserido. $\mathrm{O}$ foco de Foucault ao falar de autoria é a função que o indivíduo desempenha. É o que ele recorta, seleciona, modifica o que pode ser dito ou não em sua obra (ibid). O autor localiza-se em um lugar fronteiriço porque ao mesmo tempo em que ele é constituído por discursos, ele os mobiliza e os rompe ao classificar, reagrupar, delimitar, excluir, opor e relacionar textos uns dos outros. Eis uma das funções do autor: homogeneizar diferentes discursos que o tocam e dar sentidos a eles:

[...] mas o fato de que vários textos tenham sido colocados sob um mesmo nome indica que se estabelecia entre eles uma relação de homogeneidade ou de filiação, ou de autenticação de uns pelos outros, ou de explicação recíproca, ou de utilização concomitante. Enfim, o nome do autor funciona para caracterizar um certo modo ele ser do discurso: para um discurso, o fato de haver um nome de autor, o fato de que se possa dizer "isso foi escrito por tal pessoa", ou "tal pessoa é o autor disso", indica que esse discurso não é uma palavra cotidiana, indiferente, uma palavra que se afasta, que flutua e passa, uma palavra imediatamente consumível, mas que se trata de uma palavra que deve ser recebida de uma certa maneira e que deve, em uma dada cultura, receber um certo status. (FOUCAULT, 2001, s/n).

Autor seria dessa forma, não um indivíduo real, mas a posição de sujeito que une e delimita diversos tipos de discursos, reduzindo suas diferenças e dando-lhes coerência e uma homogeneidade (FOUCAULT, 2012, p. 25). O princípio de unidade ou agrupamento é uma das quatro "função autor" discriminadas por Foucault, classificações essas que não são universais, mas uma característica do modo de existência, de circulação e de funcionamento de certos discursos no interior de uma sociedade.

Cada discurso funciona de uma forma específica e complexa, mas quem dá sua coerência é o sujeito considerado como autor devido à função que ele exerce. Ou seja, o discurso possui marcas de uma existência pertinentes para compreender o momento e o lugar de sua produção. $\mathrm{O}$ autor se torna aquele que cria um aspecto de homogeneidade diante de uma pluralidade de posições e diversidade de vozes, selecionando-os e organizando-os de forma lógica. As outras três funções enumeradas por Foucault (2001, p. 14-18) são:

1. Apropriação: um texto possui um autor quando este pode ser punido ao praticar um gesto carregado de riscos, estabelecendo uma propriedade ao texto. Entende-se esta 
função como forma de conservar os direitos do autor sobre sua obra através de regras restritas como contratos e os direitos de copyright.

2. Valor de verdade: um texto é dotado de autoria quando o nome de um sujeito representa uma referência e uma garantia sobre o que foi escrito. Neste caso, é atribuído ao autor o valor de autoridade e credibilidade que legitima o conhecimento que está sendo transmitido e dá credibilidade como valor de verdade. Esse tipo de função surge na Modernidade, quando textos científicos passam a desafiar o sagrado.

3. Origem: a autoria é uma operação complexa e se constitui de diferentes formas de acordo com o tempo histórico e com os tipos de discursos que o constituem, mas é atribuído a esse sujeito um valor de criador, aquele que dá uma razão ao texto. Quando um texto passa por modificações, como uma atualização ou revisão, ele está sendo situado em seu momento histórico e confere a possibilidade de transformação mediante a ação de um sujeito.

Tendo por base essas considerações, podemos dizer que existe autoria no contexto de produção de livros didáticos atualmente, marcado por complexas disputas políticas e culturais, nas relações de saber/poder? Se formos considerar, a partir das ideias foucaultianas, que a autoria é uma função, então podemos dizer que sim. Existe nesse lugar de autoria um princípio de unidade, pois nesse material estão reunidos diferentes gêneros textuais a fim de construir sentidos sobre o conhecimento histórico escolar, além de obedecer às normas legais e dialogar com demandas sociais. Em meio a tantos discursos, diversos e diferentes, e sendo o próprio autor parte desse discurso, assume-se uma função de homogeneizá-los e produzir sentidos sobre o que deve ser ensinado.

Há também autoria porque assume-se a função de propriedade 5 da obra. Por mais que saibamos que um livro didático é resultado de diferentes mãos que estiveram presentes no seu processo produtivo, a obra ainda é atribuída a um nome, ou vários, em caso de coautoria. Esses sujeitos assinam um contrato e ganham direitos autorais como forma de reconhecimento daquilo que produzem. Quando é o caso de livros que são frutos de projetos editoriais, a editora passa a ser reconhecida como proprietária da obra, não somente em termos legais, mas também como reconhecimento do seu público leitor com o uso do nome da editora como uma marca ou selo de qualidade.

\footnotetext{
${ }^{5}$ Compreendemos o autor como proprietário da obra no sentido que a ele é atribuída responsabilidade sobre aquele objeto. Compreendemos que no contexto de produção a editora possui também diretos, mas a primeira referência sobre o livro normalmente é o autor, sendo assim identificado como seu proprietário.
} 
DOI: $10.47694 /$ issn.2674-7758.v2.i5.2020.117134

Outra relação possível entre a função-autor e os livros didáticos é aquela decorrente da atribuição de responsabilidade pelas informações presentes na obra. Qualquer erro ou inconsistência que sejam encontrados no livro, o nome do autor é o primeiro a ser lembrado como responsável pelo fato. Mas também os conteúdos presentes na obra são tomados como verdades que representam o conhecimento escolar a ser ensinado. Assim, mesmo que o texto seja resultado da unidade de diferentes discursos, o autor do livro é considerado o "criador" daquelas informações, tendo a sua palavra, dessa forma, um valor de verdade e origem.

Acreditamos que mesmo diante de um cenário de controle de produção de livros didáticos, obedecendo a regras para se adaptarem ao modelo do que se propõe por escola e educação, a função autor continua sendo exercida, mas nas mãos de diversos sujeitos. Assim, ser autor não é uma identidade ligada a uma pessoa, mas uma função que se constitui no momento da escrita dentro de uma determinada contingência. Nesse lugar de produção, escolhas são feitas e discursos mobilizados, configurando uma autonomia relativa.

As dimensões da função-autor são compreendidas discursivamente e estão imbricadas com os saberes que o autor mobiliza na busca de tornar os conteúdos compreensíveis pelo público a que se destina. Nesse sentido, ao operar com a teorização de Foucault, entendemos que, como uma função discursiva, podemos problematizar a autonomia desse autor. $\mathrm{O}$ sentido de autonomia aqui trabalhado não faz luz à uma independência e originalidade, como uma gênese criativa nunca vista antes. Dentro daquilo que Foucault ressalta sobre a função-autor, podemos considerar que a autonomia está situada no princípio de unidade ou agrupamento, porque a autoria é o lugar em que se dá coerência e homogeneidade aos diversos discursos por eles criados, constituídos pelos sentidos que circulam no contexto sociocultural. No movimento da produção didática, ao mobilizar outros enunciados, novos sentidos podem ser produzidos, evidenciando uma autonomia relativa do que é possível de ser dito dentro da formação discursiva na qual está inserido.

\section{Autoria de livros didáticos: novos olhares}

Quando apostamos na potencialidade do conceito de autoria, estamos interessados em compreender como se estabelecem as relações entre saber e poder, problematizando o papel daqueles que produzem livros didáticos em práticas discursivas que definem regras enunciativas em narrativas didáticas. Assim, não 
DOI: $10.47694 /$ issn.2674-7758.v2.i5.2020.117134

estamos preocupados com os indivíduos em si, físicos, materiais, independentes e originais, mas estamos trabalhando com uma ideia de sujeitos inseridos em modos de subjetivação pelo saber, poder e pelo pensamento sobre si (VEIGA-NETO, 2007).

Ser autor, dentro do campo discursivo, é algo contingente e provisório, produzido pelas próprias práticas discursivas que os constitui. Pensamos, dessa forma, que os autores são sujeitos constituídos mediante uma função que exercem dentro daquele contexto discursivo de produção entendido como um acontecimento. Mas não é qualquer sujeito que pode exercer a função de autor. De acordo com Foucault (2012), existe uma especificidade que nomeia sujeitos à essa condição de funcionamento da ordem do discurso, definindo como um princípio de rarefação, que tem como função:

[...] determinar as condições de seu funcionamento, de impor aos indivíduos que o pronunciam certo número de regras e assim de não permitir que todo mundo tenha acesso à eles. Rarefação, desta vez, dos sujeitos que falam; ninguém entrará na ordem do discurso se não satisfazer a certas exigências ou se não for, de início, qualificado para fazê-lo. (FOUCAULT, 2012, p. 35).

Assim, podemos considerar que um sujeito se torna autor quando inserido dentro de um determinado contexto, reconhecido pelos seus pares para exercer essa função. Dito isso, nos questionamos: o que é um autor de livro didático? Que contexto e condições de produção caracterizam aqueles responsáveis por uma produção curricular de tamanha importância para o processo de ensino e aprendizagem?

Responder essa questão nos leva a uma complexa análise sobre os desafios da escrita didática na contemporaneidade. Citamos aqui dois aspectos contingenciais dessa prática: as políticas públicas e o mercado editorial brasileiro. Podemos considerar que essas duas instituições, mas não somente elas, produzem enunciados que exercem práticas de poder nesse processo de produção de livros didáticos. Seguindo a concepção foucaultiana, o significante "poder" não é considerado como uma entidade materializável, uma racionalidade interna que se manifesta em um lugar específico, mas são forças, no plural, multidirecionais, difusas e capilares (FONSECA, 2011). O poder, para Foucault, passa a ser entendido em uma escala da microfísica, operando em práticas difundidas na sociedade, ações que se manifestam sobre outras ações e que, dessa forma, alteram o estado de um corpo (VEIGA-NETO, 2007).

Em relação aos impactos das políticas públicas, destacamos como o Programa Nacional de Livros Didáticos (PNLD) e a Base Nacional Comum Curricular (BNCC) têm desempenhado uma relação de poder no processo de escolha e produção desses 
materiais. Apesar de o PNLD consistir em um programa que inicialmente se concentrou sobre aspectos administrativos e logísticos de compra e distribuição de livros, foi possível perceber que, aos poucos, essa política começou a se configurar como um indutor estatal de mudanças nos livros didáticos (ROCHA, 2017), deixando aos poucos seu caráter assistencialista para servir como instrumento curricular que visa a melhoria na educação (SAMPAIO, CARVALHO, 2010). A partir de critérios avaliativos determinados por uma comissão formada por meio de edital, aqueles que produzem os livros didáticos buscam dialogar com as expectativas do que é um livro didático de qualidade, determinadas por essa comissão, a fim de que não tenham suas obras reprovadas e, consequentemente, gerando um prejuízo no número de vendas.

Dessa forma, o PNLD passa a ser um dos principais documentos que orientam as práticas de autores e editoras, adquirindo uma função curricular ao consolidar as exigências técnicas e políticas sobre os livros didáticos, adotando um papel pedagógico e disciplinador (CERRI, FERREIRA, 2007). Mas é preciso ressaltar que a política curricular implementada pelos editais do PNLD não impede a liberdade de expressão e a pluralidade teórico-metodológica nos livros didáticos, desde que não fira os direitos humanos e princípios democráticos estabelecidos em seus editais.

Já a BNCC, documento de caráter normativo implementado em 2017, tem mobilizado todo o cenário educacional a fim de adequação curricular do que seriam os princípios educativos a serem seguidos em todos os níveis de ensino, por todos os componentes curriculares, em todo o país. E essa medida certamente impactou também a produção de livros didáticos que teve que adequar os conteúdos de acordo com as habilidades estabelecidas no documento. Por ser um movimento relativamente recente, ainda não nos debruçamos, no momento de produção deste artigo, a investigar os impactos dessa política no objeto desta pesquisa.

Essas políticas públicas causam impacto no perfil daqueles que escrevem livros didáticos. Se antes o lugar de autoria vinha sendo ocupado por sujeitos que se consagraram como referência na área na década de 1990, aos poucos, esse espaço foi sendo ocupado por profissionais que se caracterizam por apresentar uma preparação maior para estabelecer um diálogo com as diretrizes curriculares oficiais. As próprias editoras passaram a contratar como autores, pessoas especializadas em discussões mais atuais do campo de ensino e que possam produzir livros menos ortodoxos (SAMPAIO, CARVALHO, 2010). 
O segundo aspecto que se situa na rede de poderes que compõem enunciados discursivos na produção de livros didáticos é o papel das editoras. Podemos retomar aqui a contribuição de Munakata (1997) e Gatti Jr (2004) que se voltam para essa relação entre autores e editores. Os casos analisados por ambos pesquisadores alertam para um aspecto mercadológico que tem mobilizado uma diversidade de agentes para além do autor. Poderíamos considerar uma interferência a participação desses outros sujeitos que tomam decisões nesse processo de produção, distribuição e divulgação da mercadoria? As editoras ocupariam um lugar de instituição disciplinadora que exerce seu poder de forma a regular as práticas desempenhadas no lugar de autoria? Sim, esta é uma possibilidade que vem sendo desenvolvida por esses pesquisadores, mas não é o olhar que queremos explorar neste artigo.

O campo editorial vem ganhando cada vez mais destaque e protagonismo no processo de produção de livros didáticos. Pode-se observar, ao longo da trajetória de produção dos livros didáticos no Brasil, que houve um aumento expressivo no número de empresas que contratam o trabalho de intelectuais a fim de aprimorá-los e impulsionar as vendas desses materiais. Se antes as obras didáticas eram reconhecidas, na comunidade escolar, pelo nome daquele que escreve (por exemplo, "o livro do Koshiba"), os grandes projetos editoriais vêm ocupando espaço como referência de propostas didáticas. Novos títulos surgiram no mercado, com ampla divulgação de suas propostas didáticas alardeadas pelo teor de novidade e renovação alcançado nas obras. Os autores, ou a equipe editorial, são continuamente substituídos, promovendo a consagração de alguns sujeitos já famosos e permitindo o surgimento de novos nomes nesse meio (SOUZA, 1996).

Quando nos referimos a autoria, é importante salientar, com base nas contribuições de Foucault, que não se trata de um sujeito responsabilizado pela escrita da obra. Essa atribuição de função não se situa somente no papel de uma pessoa, mas de uma equipe ampla que atua desde o projeto até a impressão do livro em sua versão final. Estão incluídos aí editores, ilustradores, designers gráficos, revisores, dentre muitos outros. Todos eles atuam produzindo significados sobre o que deve ser ensinado. Assim, defendemos que a editora, composta por essa variedade de funcionários, também constitui parte da autoria porque passa a exercer também a função-autor.

Ainda, analisando o que/quem é o autor de livro didático na atual conjuntura educacional, gostaríamos de refletir sobre o reconhecimento social desses sujeitos. Sem dúvida trata-se de um trabalho complexo, com muitas idas e vindas, impeditivos de 
diversas ordens para que, no final, possamos ter um produto de qualidade e atraente para seu público. Mesmo assim, identificamos pouco reconhecimento no meio acadêmico. Se analisarmos o perfil desses sujeitos na Plataforma Lattes, por exemplo, há pouca divulgação de suas atuações como produtores de obras didáticas e, quando o registro é feito, está listado como produção técnica, e não produção intelectual que, em um concurso público, possui valor menor se comparada a de artigos e capítulos de livros científicos. Esta situação é decorrente da concepção que orienta o registro das produções na Plataforma Lattes e que não reconhece a produção de livros didáticos como produção intelectual, confirmando uma perspectiva hierarquizante que subestima o conhecimento escolar. Conforme exposto na introdução deste artigo, defendemos que esta produção é complexa e apresenta características culturais diferenciadas que precisam ser consideradas.

Defendemos que é importante reconhecer a atuação desses profissionais na educação. Gatti Jr (2004) relata que na década de 1990, a produção de livros didáticos não era uma atividade central na carreira de alguns autores, que mantinham essa profissão de forma concomitante com a carreira de professores da educação básica ou do ensino superior. Hoje, já percebemos uma alteração nesse cenário, com um aumento significativo de escritores que tomaram a produção de livros didáticos uma profissão de dedicação exclusiva, o que indica que houve uma mudança em relação à essa prática. Tem sido preciso se concentrar mais nas regras de produção, obedecer aos apertados prazos para revisão e participar da divulgação do livro, percorrendo o país oferecendo palestras pela editora ou por convites de escolas e associações. Isso tem levado a estarem menos presentes em sala de aula (MUNAKATA, 2016; GATTI JR, 2004).

Com tantos sujeitos envolvidos no processo produtivo de livros didáticos, poderíamos afirmar que não existe mais autoria? Não, pelo contrário. Nossa proposta é trazer outro olhar sobre o que é ser autor. Por isso é importante colocar a autoria em questão, pois não se trata de uma função representada por um sujeito, mas sim desempenhada atualmente pelas mãos de muitos. Resgatando a teorização foucaultiana explorada na primeira parte deste artigo, quando passamos a compreender a autoria não como uma identidade, mas uma função discursiva, nos desprendemos de materialidades que ligam o processo criativo a um nome. Se a autoria está ligada às funções discursivas de unidade, apropriação, valor de verdade e origem, precisamos rever a quem são atribuídas essas funções. 
DOI: $10.47694 /$ issn.2674-7758.v2.i5.2020.117134

É preciso reconhecer quem são esses novos sujeitos que ocupam essa função para compreender como ela continua sendo desempenhada. Por isso propormos olhar para a ação das editoras como parte constituinte da autoria, pois ali há também uma mobilização de saberes e poderes que produzem sentidos e conhecimentos. $\mathrm{O}$ resultado dessa ação ganha a forma de livros didáticos que serão apropriados por professores e estudantes de todo o país.

\section{Considerações finais}

Nas duas últimas décadas, autores brasileiros têm desenvolvido estudos e pesquisas nas quais os livros didáticos são abordados a partir do reconhecimento de que são objetos culturais complexos e cuja produção envolve questões econômicas e políticas em disputas por espaço no mercado editorial e aceitação no âmbito das políticas educacionais. Mesmo assim, é possível observar que a autoria de livros didáticos ainda ocupa um lugar secundarizado em relação a outras posições no meio científico e literário, nas quais reconhecimento e prestígio são atribuídos a sujeitos que se destacam com suas produções. Em grande parte decorrente da desvalorização da cultura escolar e dos conhecimentos ali produzidos, vistos como simplificações, reducionismos e/ou distorções do conhecimento científico, esta situação gera preconceitos e discriminações em relação às práticas e saberes desenvolvidos na instituição escolar e nos materiais pertinentes, incluindo os livros didáticos.

Em nosso programa de pesquisas (MONTEIRO, 2019) temos investido na análise e busca da compreensão da produção curricular em diferentes contextos, tendo como pressuposto que esta se constitui como híbrido cultural que articula diferentes saberes para atribuição de sentidos aos fenômenos e processos sócio-político-culturais, produção complexa que tem na relação com o conhecimento científico uma contribuição referencial mas não exclusiva. Reconhecendo a dimensão produtiva do currículo, temos investigado, também, a relação dos docentes com os saberes que ensinam, considerando características específicas da área disciplinar, no caso em pauta, a História.

Considerando que autores de livros didáticos estabelecem relações com os saberes em sua produção do conhecimento escolar, e avançando para além das perspectivas que subordinam esta produção frente ao conhecimento científico, esta autoria constituiu-se em questão, que teve no diálogo com as teorizações foucaultianas sobre discurso e arqueologia do saber um instrumento potente para pensar este objeto 
DOI: 10.47694/issn.2674-7758.v2.i5.2020.117134

com outras lentes e ferramentas teóricas. A superação de dicotomias e binarismos paralisantes possibilitou ampliar o espectro da análise e, tendo por base a concepção de autoria como função discursiva, desenvolvemos argumentação para investigar as possibilidades heurísticas desta abordagem no contexto contemporâneo no qual as novas configurações das editoras criam possibilidades produtivas em meio a normas legais e interesses econômicos no Brasil.

Nesse sentido, entendemos que discutir a autoria não valorizada de livros didáticos em diálogo com as teorizações foucaultianas, pode se constituir em contribuição relevante para a compreensão dos processos envolvidos no fazer curricular, no qual inserimos a produção didática. A relação com os saberes se expressa, de forma própria, nas seleções e encaminhamentos definidos para esses objetos culturais complexos. Usos do passado dizem de um presente cuja "invenção" agentes estatais e privados têm procurado controlar, mas que também se mantêm abertos a múltiplas leituras e apropriações por autores e leitores, em possibilidades de exercício da prática de liberdade.

\section{Referências}

BALL, Stephen. J. "Diretrizes políticas globais e relações políticas locais em educação". Currículo sem fronteiras, v1, n.2, p.99-116, 2001.

BARTHES, Roland. O Rumor da Língua. São Paulo: Martins Fontes, 2004.

BITTENCOURT, Circe. Autores e editores de compêndios e livros de leitura (18101910). Educação e Pesquisa, v. 30, n.3, 2004, p. 475-491.

Livro didático e saber escolar 1810-1910. 1. ed. Belo Horizonte: Autêntica Editora, 2008.

CASSIANO, Celia Cristina de Figueiredo. O mercado do livro didático no Brasil do século XXI: a entrada do capital espanhol na Educação nacional. São Paulo: Editora Unesp, 2013.

CERRI, Luís. Fernando.; FERREIRA, Ângela Ribeiro. Notas sobre as demandas sociais de representação e os livros didáticos de História. In: OLIVEIRA, Margarida Maria Dias de; STAMATTO, Maria Inês S. (org.). O livro didático de história: políticas educacionais, pesquisas e ensino. Natal: EDUFRN, 2007.

CHARLOT, Bernard. Du rapport au savoir. Éléments pour une théorie. Paris: Ed Economica, 1997.

CHARTIER, Roger. A ordem dos livros: leitores, autores e bibliotecas na Europa entre os séculos XIV e XVIII. Brasília: Editora Universidade de Brasília, 1994. 
DOI: 10.47694/issn.2674-7758.v2.i5.2020.117134

CHARTIER, Roger. A mão do autor e a mente do editor. São Paulo: Editora UNESP, 2014.

FISCHER, Rosa Maria Bueno. Foucault e a análise do discurso em educação. Cadernos de Pesquisa, n. 114, p. 197-223, nov/2001.

FONSECA, Marcia A. Michel Foucault e a constituição do sujeito. 3. ed. São Paulo: EDUC, 2011.

FOUCAULT, Michel. O que é um autor? Ditos e Escritos: Estética - literatura e pintura, música e cinema (vol. III). Rio de Janeiro: Forense Universitária, 2001. p.264298.

A ordem do discurso: aula inaugural no Collège de France, pronunciada em 2 de dezembro de 1970. 22ª ed. São Paulo: Edições Loyola, 2012.

GABRIEL, Carmen Teresa. MORAES, Luciene Maciel Stumbo. Conhecimento escolar e conteúdo: possibilidades de articulação nas tramas da didatização. In: GABRIEL, Carmen Teresa.; MORAES, Luciene Maciel Stumbo (org.) Currículo e conhecimento: diferentes perspectivas teóricas e abordagens metodológicas. Petrópolis: De Petrus: Faperj, 2014.

GASPARELLO, Arlette Medeiros. Livro didático e história do ensino de História: caminhos de pesquisa. In: GALZERANI, Maria. Carolina Bovério; BUENO, João Batista Gonçalves; PINTO JR, Arnaldo. (org.) Paisagens da pesquisa contemporânea sobre o livro didático de História. Paco Editorial; Campinas: Centro de Memória/ Unicamp, 2013

GATTI JR, Décio. A escrita escolar da História: livro didático e ensino no Brasil (1970-1990). Bauru/SP: EDUSC. Uberlândia/MG: EDUFU, 2004

Estado, Currículo e Livro Didático de História no Brasil (1988-2007). In: OLIVEIRA, Margarida Maria Dias de; STAMATTO, Maria Inês Sucupira (org.). $O$ Livro Didático de História: políticas educacionais, pesquisas e ensino. 1ed. Natal/RN: EDUFRN, 2007, p. 19-35.

MACEDO, Elizabeth. Currículo: política, cultura e poder. Currículo sem Fronteiras, v. 6, n. 2, pp.98-113, jul/dez, 2006.

MONTEIRO, Ana Maria. Professores e livros didáticos: narrativas e leituras no ensino de História. In: ROCHA, Helenice; REZNIK, Luís; MAGALHÃES, Marcelo (org.). A história na escola: autores, livros e leituras. Rio de Janeiro: Editora da FGV, 2009.

Aulas de História: questões do/no tempo presente. Educar em Revista, Curitiba, Brasil, n. 58, p. 165-182, out./dez., 2015

Os saberes dos professores sobre os conhecimentos que ensinam: trajetórias de pesquisa em Ensino de História. In: MONTEIRO, Ana Maria; RALEJO, Adriana (org.) Cartografias da Pesquisa em Ensino de História. Rio de janeiro: Mauad X, 2019 
MUNAKATA, Kazumi. Produzindo livros didáticos e paradidáticos. Tese (Doutorado em Educação). Pontifícia Universidade Católica de São Paulo, São Paulo, 1997.

Devem os livros didáticos de história ser condenados?. In: ROCHA, Helenice; MAGALHÃES, Marcelo de Souza.; GONTIJO, Rebeca. (orgs.). A escrita da história escolar: memória e historiografia. 1ed.Rio de Janeiro: FGV, 2009, v. 1, p. 281-292.

Os autores de livros didáticos na virada do século. In: GAPARELLO, Arlette Medeiros.; VILLELA, Heloísa. (orgs.) Educação na história: intelectuais, saberes e ações instituintes. Rio de Janeiro: MAUAD X, 2016.

RALEJO, Adriana. "Lugar de autoria”: Contingências, desafios e possibilidades na produção de livros didáticos de História. Tese (Doutorado em Educação). Universidade Federal do Rio de Janeiro, Rio de Janeiro, 2018

ROCHA, Helenice. Livro didático de história em análise: a força da tradição e transformações possíveis. In: ROCHA, Helenice; REZNIK, Luís; MAGALHÃES, Marcelo. (org.) Livros didáticos de história: entre políticas e narrativas. Rio de Janeiro: FGV Editora, 2017.

SAMPAIO, Francisco Azevedo de Arruda; CARVALHO, Aloma Fernandes de. Com a palavra, o autor: em nossa defesa: um elogio à importância e uma crítica às limitações do Programa Nacional do Livro Didático. São Paulo: Editora Sarandi, 2010.

SOUZA, Deusa Maria. Autoridade, autoria e o livro didático. Contexturas: Ensino crítico de Língua Inglesa, São Paulo, n. 3, p. 55-60, 1996.

VEIGA-NETO, Alfredo. Foucault \& a Educação. 2. ed. Belo Horizonte: Autêntica, 2007

VILELA, Carolina Lima. Currículo de geografia: analisando o conhecimento escolar como discurso. Tese (Doutorado em Educação). Universidade Federal do Rio de Janeiro. Rio de Janeiro, 2013

Artigo recebido em 07 de julho de 2020. Aprovado em 18 de agosto de 2020. 